\title{
Q1 Análise do comportamento dos consumidores de feiras livres na microrregião de Formiga (MG)
}

Danielle Martins Duarte Costa ${ }^{1}$

Diego César Terra de Andrade ${ }^{2}$

Samara Luis Felipe ${ }^{3}$

\section{Resumo}

O artigo analisou os principais fatores social, econômico e cultural que influenciaram a decisão de compra dos consumidores de feiras livres da microrregião de Formiga, Minas Gerais. Os resultados indicaram características comportamentais marcadas por variáveis que valorizam a qualidade de vida, economia de tempo e dinheiro e valores sociais, como o convívio social, influenciando a conduta de consumo. Em sua maioria, os consumidores são famílias de baixa e média renda.

Palavras-chave: Variáveis comportamentais. Agricultura familiar. Minas Gerais. Decisão de compra.

\section{Introdução}

As feiras livres podem ser classificadas como instrumentos de desenvolvimento sociocultural e econômico e, apesar dos "tempos modernos" e dos contratempos que elas podem causar em grandes cidades, elas não desapareceram e convivem com o comércio varejista (ÂNGULO, 2011). Em lugares no interior do país, elas são, por vezes, o único local de abastecimento de alimentos frescos e produtos artesanais, produzidos com características regionais e, em sua grande maioria, em pequena escala (SILVESTRE; CALIXITO; RIBEIRO, 2005; ÂNGULO, 2011). Para Ribeiro et al. (2005), quanto menor o município, maior o impacto que a feira exerce. No interior de Minas Gerais, por exemplo, as feiras livres são caracterizadas como parte da tradição mineira (RIBEIRO et al., 2005).

Quanto aos aspectos econômicos, sociais e culturais, estudos trazem evidências dos ganhos financeiros e econômicos desse mercado, da valorização da cultura local e dos produtos locais, além dos aspectos éticos em relação ao consumo nas feiras livres (MARTINEZ, 2010; THILMANY; BOND; BOND, 2008).

Do ponto de vista econômico, os feirantes reunidos vendem uma produção que não alcançaria em outros mercados, uma vez que os produtos comercializados, muitas vezes, estão ligados à cultura alimentar local. Além disso, a relação direta entre o feirante e o consumidor possibilita a diminuição dos custos de comercialização, que envolve insumos, transporte e embalagens. Essa diminuição faz com que as feiras se coloquem como canais potencialmente mais eficientes (RICOTTO, 2002). Nesse sentido, as feiras livres são importantes para a consolidação econômica da agricultura familiar, sendo capazes de provocar mudanças e reconversão no setor de pequenos e médios agricultores (RICOTTO, 2002).

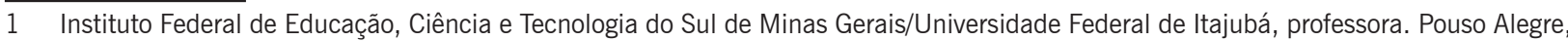
Minas Gerais, Brasil. danielle.costa@ifsuldeminas.edu.br. Avenida Maria da Conceição Santos, n. 900, Bairro Parque Real, Pouso Alegre (MG) - CEP 37550-000.

2 Instituto Federal de Educação, Ciência e Tecnologia do Sul de Minas Gerais/Universidade Nove de Julho, professor. Pouso Alegre, Minas Gerais, Brasil. diego.terra@ifsuldeminas.edu.br. Avenida Maria da Conceição Santos, n. 900, Bairro Parque Real, Pouso Alegre (MG) - CEP 37550-000.

3 Centro Universitário de Formiga, Formiga, Minas Gerais, Brasil. samaraluis@yahoo.com.br. Avenida Doutor Arnaldo de Senna, 328, Água Vermelha - Formiga (MG). 
Quanto ao aspecto social e cultural, Gogoy e Anjos (2007) argumentam que as feiras livres proporcionam a aproximação e a troca de experiências entre os agricultores-agricultores e agricultores-consumidores em um alto nível de confiança. De acordo com as observações dos autores, essa troca de saberes traduz-se na forma de receitas de preparo dos alimentos, informações nutricionais e informações técnicas de produção agroecológicas.

Em resumo, as feiras livres figuram-se como um verdadeiro elemento estruturante da organização social e econômica das populações (ÂNGULO, 2011). Nela a pequena produção familiar pode ser transformada em numerário, que, por sua vez, converte-se em renda e consumo. Nas feiras gera-se o consumo que dinamiza o comércio dos municípios. É a partir delas que se moldam os hábitos alimentares das comunidades em que os consumidores urbanos e rurais buscam a produção da lavoura e da indústria doméstica rural. Isso pode ocorrer desde os alimentos básicos, passando pelas frutas da estação e chegando aos doces e quitutes que agradam aos mais diferentes gostos (RIBEIRO et al., 2005).

Portanto, analisar as variáveis que mais influenciam a decisão de compra dos consumidores de feiras livres é de extrema importância para a preservação desse tipo de comércio local, manutenção da renda das famílias envolvidas e das tradições culturais e sociais advindas dessa prática.

Além disso, de acordo com Barros, Lopes e Wanderley (2008), as informações sobre as preferências dos consumidores são úteis para os feirantes, pois esses poderão balizar o aumento ou redução da oferta de determinados produtos, dimensionando demandas e ofertas, planejando áreas de plantio, investimentos a serem feitos em suas propriedades e tecnologias a serem praticadas em seus sistemas de produção, entre outras. É nessa afirmação que se justifica a realização desta pesquisa.

Neste sentido, o artigo tem como objetivo principal caracterizar e analisar os principais fatores sociais, econômicos e culturais que influenciam os consumidores em suas decisões de compras nesse tipo de mercado. Para tanto, a unidade de observação deste trabalho foram as feiras livres dos municípios da microrregião da cidade de Formiga, estado de Minas Gerais, e a unidade de análise foi os consumidores dessas feiras livres.

\section{Comportamento do consumidor}

De acordo com Vilas Boas (2005), entender as razões que motivam um indivíduo ou grupo de pessoas a adquirir determinado produto tem sido um dos maiores desafios empreendidos pelos estudiosos da teoria de marketing. Desenvolver mecanismos e modelos de aplicabilidades práticas capazes de auxiliar na identificação de fatores motivadores do consumo tem se caracterizado como uma das grandes linhas de pesquisa relacionadas ao estudo do comportamento do consumidor.

O processo de escolha, ou a tomada de decisão, do consumidor resume-se em um conjunto de processos envolvidos no reconhecimento de problemas, na busca de soluções, na avaliação de alternativas, na escolha entre opções e na avaliação dos resultados da escolha (SOLOMON, 2002). Os consumidores tomam decisões considerando quais opções de produto e marcas escolher e que quantidade de produtos comprar. Eles tomam decisões com o intuito de alcançar melhores objetivos, o que inclui fazer a melhor escolha entre duas ações, reduzir o esforço da tomada de decisão, minimizar emoções negativas e maximizar a capacidade de justificar a decisão.

A tomada de decisão é um processo construtivo (SHETHH; GARDNER; GARRETT, 1988). Ou seja, os consumidores tomam decisões continuamente e o processo empregado é influenciado pela dificuldade do problema, pelo conhecimento, pelas características do consumidor e pelas características da situação. Podemos considerar três perspectivas de tomada de decisão: a perspectiva tradicional, a experimental e a comportamental. 
A perspectiva tradicional da tomada de decisão consiste em uma abordagem racional do processamento de informação para o comportamento de compra (KOTLER, 1998). De acordo com essa abordagem, os consumidores passam de maneira linear por todos os estágios do processo de decisão, quando ocorrem altos níveis de processamento de informação. No entanto, os pesquisadores perceberam que os consumidores nem sempre passam por um longo processo de decisão. Em vez disso, sob condições de baixo envolvimento, ocorre a tomada de decisão limitada, cujo estágio de busca de informação é reduzido.

De acordo com Foxall (2003), a perspectiva experimental considera que os consumidores tanto sentem quanto pensam, ou seja, eles consomem muitos tipos de produtos pelas sensações, sentimentos, imagens e emoções que os produtos geram. A perspectiva experimental reconhece que os produtos carregam significados simbólicos subjetivos para os consumidores.

Ao abordar problemas a partir da perspectiva da influência comportamental, os pesquisadores atentam para os comportamentos dos consumidores e para as contingências do ambiente capazes de influenciar esses comportamentos. Por exemplo, o ambiente físico pode ser usado para induzir o comportamento dos consumidores (KINJO; IKEDA, 2005).

Nesse sentido, Kotler (1998) afirma que o comportamento de compra é influenciado por quatro fatores básicos: culturais, sociais, pessoais e psicológicos.

Os fatores culturais exercem a mais ampla e profunda influência sobre o comportamento do consumidor. Elementos que o compõem: cultura, subcultura e classe social. A cultura é um dos meios mais importantes pelos quais uma sociedade influencia o comportamento dos indivíduos, é "o complexo de valores e comportamentos apreendidos que são compartilhados por uma sociedade e destinam-se a aumentar sua probabilidade de sobrevivência" (CHURCHILL; PETER,2000).

Kinjo e Ikeda (2005) mencionam ainda que a cultura é o determinante dos desejos e do comportamento de uma pessoa. A criança em crescimento adquire um conjunto de valores, percepções, preferências e comportamentos por meio da vida familiar e de outras instituições básicas, sendo que cada cultura é constituída por subculturas, que fornecem identificação e socialização mais específicas para seus membros.

A subcultura é definida pelos autores como "uma subdivisão da cultura nacional" com base em algumas características unificadoras e cujos membros compartilham padrões semelhantes de comportamento que são distintos daqueles da cultura nacional.

Segundo Churchill e Peter (2000), subculturas são segmentos existentes dentro de uma cultura. Esses segmentos compartilham valores e padrões de comportamentos distintos que diferem dos pertencentes à cultura geral.

Classes sociais são divisões relativamente homogêneas e duradouras de uma sociedade, são ordenadas hierarquicamente e os membros compartilham valores, interesses e comportamento similares (KINJO; IKEDA, 2005).

Churchill e Peter (1998) ainda definem classe social como uma hierarquia de status nacional pela qual indivíduos e grupos são classificados em termos de valor e prestígio, com base em sua riqueza, habilidade e poder.

Os grupos de referência de uma pessoa são aqueles que exercem alguma influência direta (face to face) ou indireta sobre as atitudes ou o comportamento dessa pessoa. Os grupos que exercem influência direta sobre uma pessoa são chamados grupos de afinidade.

Alguns grupos de afinidade são primários, tais como: família, amigos, vizinhos e colegas de trabalho, com os quais a pessoa interage contínua e informalmente. As pessoas também pertencem a 
grupos secundários, como grupos religiosos e profissionais e associações de classe, que normalmente são formais e exigem menor interação contínua (KOTLER, 1998).

As decisões do comprador também são influenciadas por características pessoais, como idade e estágio do ciclo de vida do produto, estilo de vida (VILAS BOAS, 2005). As pessoas compram diferentes artigos e serviços durante a vida. Elas consomem alimentos para bebês nos primeiros anos de vida, a maioria dos alimentos durante as fases de crescimento e maturidade e dietas especiais nos últimos anos de vida. 0 gosto, no que diz respeito a roupas, móveis e lazer também é relacionado à idade. Os padrões de consumo são moldados de acordo com o ciclo de vida da família. Da mesma forma, a ocupação de uma pessoa também influencia seu padrão de consumo, à medida que é a fonte geradora de renda, além dos profissionais que exercem a mesma função compartilharem valores e gostos semelhantes. A escolha de produtos é bastante afetada pelas condições econômicas que consistem em renda disponível (nível, estabilidade e período de tempo), poupança e patrimônio, dívidas, condições de crédito e atitude em relação às despesas versus poupança.

Um estilo de vida é o padrão de vida da pessoa expresso por atividades, interesses e opiniões. 0 estilo de vida representa a 'pessoa por inteiro' interagindo com seu ambiente.

Quanto aos fatores psicológicos, quatro podem ser citados: motivação, percepção, aprendizagem e atitudes. A motivação é baseada pelos impulsos, anseios ou desejos que iniciam a sequência de eventos que a levam a uma ação. 0 conhecimento do consumidor, sendo esse um conjunto formado por percepções, aprendizagem e atitudes, é fator condicionante no processo decisório à medida que o consumidor passa a fazer distinções mais apuradas entre as marcas (KOTLER, 1998).

Portanto, a decisão de compra de uma pessoa é o resultado de uma complexa interação de fatores culturais, sociais, pessoais e psicológicos. Muitos desses fatores não podem ser influenciados pelos profissionais de marketing. Entretanto, eles são úteis para identificar os compradores que podem estar mais interessados no produto. Outros fatores estão sujeitos à influência profissional de marketing e o sugestionam sobre como desenvolver o produto, preço, distribuição e promoção para atrair uma resposta mais forte do consumidor.

Existem quatro tipos de situações que influenciam os consumidores na tomada de decisão: ambiente físico, ambiente social, tempo e estados antecedentes. Essas também serão estudadas e analisadas em uma pesquisa exploratória em municípios da microrregião de Formiga, estado de Minas Gerais.

\section{Metodologia}

\section{Delineamento do estudo}

O presente estudo é uma pesquisa de campo (LAKATOS; MARCONI, 1995; VERGARA, 2000), exploratório-descritiva (GIL, 2002; VERGARA, 2000), com abordagens qualitativa e quantitativa (DEMO, 2002), caracterizando uma triangulação dos métodos (JICK, 1979), nos moldes de um estudo de caso único (BECKER, 1999; ROESCH, 1999; SILVA; GODOI; BANDEIRA-DE-MELLO, 2006; YIN, 2001 ;).

Exploratório-descritiva, pois busca compreender quais fatores são capazes de influenciar os consumidores (unidade de análise) em suas decisões de compra nesse tipo de mercado e descreve as principais características sociais, econômicas e culturais dos consumidores de produtos agrícolas nas feiras livres (unidade de observação) da microrregião de Formiga, estado de Minas Gerais.

De acordo com Gil (2002), uma pesquisa pode ser considerada de natureza exploratória quando requer levantamento bibliográfico, entrevistas ou questionários com pessoas que tiveram experiências práticas com o objeto estudado e análise de exemplos que estimulem a compreensão. 0 
autor expõe ainda que a pesquisa exploratória pode ser realizada com uma pequena amostra e visa proporcionar uma visão geral de um determinado fato.

Já a pesquisa descritiva tem por premissa buscar a resolução de problemas melhorando as práticas por meio da observação, análise e descrições objetivas, por meio de entrevistas ou questionários com peritos para a padronização de técnicas e validação de conteúdo (THOMAS, NELSON; SILVERMAN, 2007).

Segundo Gil (2002), a pesquisa descritiva usa padrões textuais, como, por exemplo, questionários para identificação do conhecimento, e tem por finalidade observar, registrar e analisar os fenômenos sem, entretanto, entrar no mérito de seu conteúdo. Na pesquisa descritiva não há interferência do investigador, que apenas procura perceber, com o necessário cuidado, a frequência com que o fenômeno acontece. É importante que se faça uma análise completa desses questionários para que se chegue a uma conclusão.

As abordagens qualitativas nesta pesquisa se relacionam à observação não participante dos pesquisadores. Por outro lado, a parte quantitativa está relacionada à aplicação do questionário estruturado.

O Método do Estudo de Caso é "um meio de organizar dados sociais preservando o caráter unitário do objeto social estudado" (GOODE; HATT, 1969, p.422). Tull e Hawkins (1976, p 323) afirmam que "um estudo de caso refere-se a uma análise intensiva de uma situação particular". Yin (2001, p. 23) explica que "o estudo de caso é uma inquirição empírica que investiga um fenômeno contemporâneo dentro de um contexto da vida real, quando a fronteira entre o fenômeno e o contexto não é claramente evidente e em que múltiplas fontes de evidência são utilizadas".

\section{Amostra de pesquisa}

Para este estudo foram selecionadas as feiras livres existentes nos municípios da microrregião de Formiga, Minas Gerais, e que funcionavam apenas aos sábados.

Segundo classificação dada pela Assembléia Legislativa do Estado de Minas Gerais (ALMG, 2015), os municípios pertencentes à microrregião de Formiga (MG) são os descritos na tabela 1.

Tabela 1. Municípios da microrregião de Formiga (MG), e número de habitantes.

\begin{tabular}{lcl}
\hline Município & População (hab.)i & Distância de Formiga (MG) (em Km) $)^{\mathrm{iii}}$ \\
\hline Arcos & 38.946 & 30,4 \\
Camacho & 3.109 & 88,9 \\
Córrego Fundo & 6.207 & 17,0 \\
Formiga & 68.040 & - \\
Itapecerica & 22.109 & 68,5 \\
Pains & 8.351 & 35,7 \\
Pedra do Indaiá & 4.021 & 49,1 \\
Pimenta & 8.655 & 46,6
\end{tabular}

ALMG (2015). Fonte: <https://www.almg.gov.br/consulte/info_sobre_minas/index.html?aba=js tabMicrorregioes\&stlMicroregiao $=44>$

iilBGE (2015). Fonte: <http://www.cidades.ibge.gov.br/xtras/uf.php?lang=\&coduf=31\&search=minas-gerais > iii Google Maps. Fonte: <https://www.google.com.br/maps/place/Formiga,+MG/@-20.4685831,45.5065859,12z/data =!3m1!4b1!4m2!3m1!1s0x94b4ee75c615b023:0xb8255798f2161625?hl=pt-BR>

Todos os municípios tinham pelos menos uma configuração de feira livre presente pelo menos uma vez na semana, no entanto, com volumes de negócios, número de barracas e dias de feira bem 
variados. Considerou-se feira livre neste estudo a presença de pelo menos três barracas de comercialização de verduras, hortaliças, artesanatos, produtos lácteos e produtos de origem animal e vegetal.

No entanto, dos oito municípios que formam a microrregião de Formiga, apenas dois foram selecionados para este estudo: Formiga e Arcos.

Esses dois municípios foram selecionados por reunir todas as características abaixo:

a) Juntos, esses municípios representam $67,10 \%$ da população total da microrregião de Formiga;

b) Esses dois municípios tinham feiras livres todos os sábados e com volumes próximos de barracas e pessoas circulando e,

c) Pela facilidade de aplicar os questionários, dada a proximidade de ambos os municípios. A distância entre eles é de 30,4 km.

\section{Coleta e tratamento dos dados}

Os dados da pesquisa foram coletados por um dos pesquisadores, por meio de um questionário estruturado, com respostas fechadas, ou seja, com respostas do tipo "sim" e "não".

As perguntas dos questionários foram elaboradas com base nos fatores influenciadores do comportamento dos consumidores, conforme descrito por Kotler (1998) e mencionado na seção anterior, quais sejam: variáveis pessoais e sociais (que caracterizam o perfil socioeconômico) e variáveis culturais e psicológicas (que caracterizam o perfil cultural).

Os questionários foram direcionados aos consumidores das feiras livres que ocorriam somente aos sábados, localizadas nos municípios de Arcos e Formiga. Em ambas as cidades, as feiras iniciavam-se às 06h da manhã, com término às 13h, aproximadamente, portanto, 07 horas de duração. Ao todo, foram aplicados 100 questionários.

Paralelamente à aplicação do questionário, foi realizada uma pesquisa por observação, em que foi possível anotar algumas atitudes, comentários e situações vistas no local e que não estavam abrangidas nas perguntas dos questionários.

Todos os dados foram coletados no período de junho e agosto de 2011.

Com o resultado das duas pesquisas, foi possível enriquecer os resultados.

Inicialmente, buscou-se uma leitura da formação das feiras livres nesses municípios, enfatizando possíveis diferenciações sociais e espaciais, sobretudo no que diz respeito à localização de tais feiras no contexto geográfico das cidades. Em seguida, procurou-se, por meio dos questionários, analisar e caracterizar o perfil dos consumidores que frequentam essas feiras a fim de analisar os fatores que influenciam o comportamento dos consumidores das feiras livres da região do estudo.

Após a coleta dos dados foi realizada a análise e tabulação dos dados utilizando os aplicativos simples do software Excel ${ }^{\circledR}$.

\section{Resultados e discussões}

Inicialmente foram analisados os fatores, valores pessoais e sociais, a fim de caracterizar o perfil socioeconômico dos consumidores de feiras livres dos municípios analisados.

Dos entrevistados, 56 \% eram do sexo feminino e $44 \%$ do sexo masculino. Do total, $60 \%$ estavam casados ou em regime de união estável e o restante se separaram ou estão solteiros. Apesar de se observar pessoas com crianças e jovens, não foi possível identificar se os filhos teriam alguma influência sobre a escolha dos consumidores, uma vez que houve durante a aplicação do questionário 
uma grande discrepância de informações. Havia casais cujos filhos já não moravam em casa, outros que não tinham filhos e outros que moravam com pais ou parentes.

A faixa etária dos entrevistados apresentou uma variação considerável: 67,5 \% possuíam de 31 a 50 anos de idade, enquanto 32,5 \% estavam acima dos 51 anos de idade. Chama atenção o fato de nenhum dos entrevistados possuir idade abaixo de 30 anos, conforme destaca a Figura 1. Esses resultados confirmaram a pesquisa por observação, na qual foi notado que a maioria dos consumidores era adulta. Havia alguns jovens que apareciam principalmente no final da feira e poucos idosos.

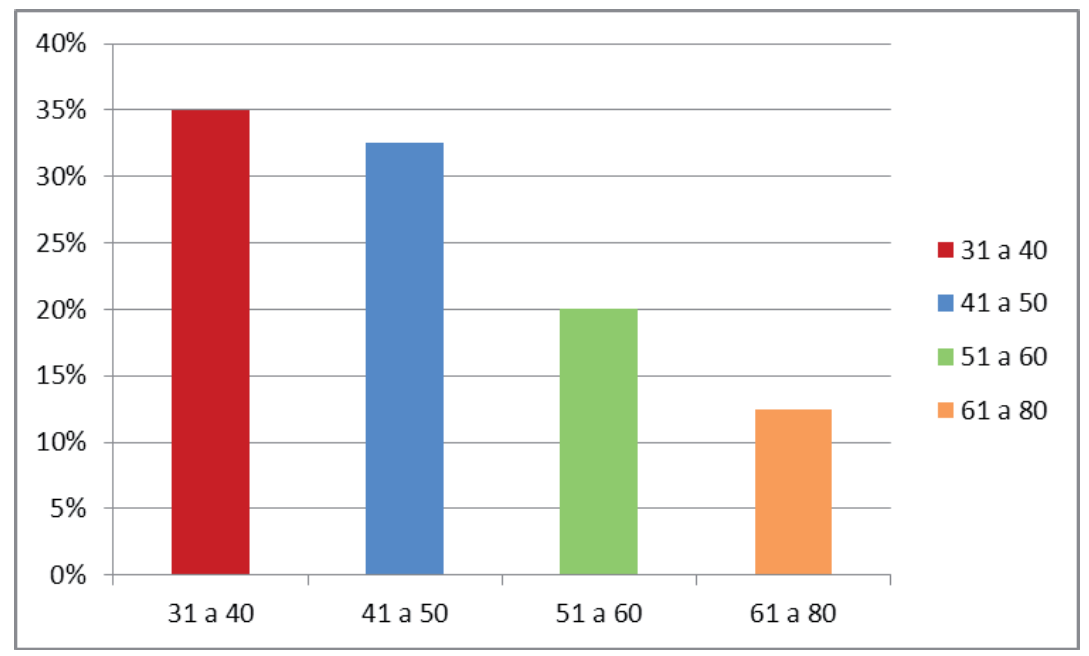

Figura 1. Faixa etária dos consumidores das feiras livres nos municípios de Arcos e Formiga (MG). Fonte: Elaboração dos autores.

O Grau de escolaridade pode explicar o desenvolvimento recente na educação superior da região pesquisada. Os dados apontaram que apenas $35 \%$ dos consumidores possuíam ensino superior completo. A Figura 2 apresenta maiores detalhes sobre essa variável demográfica.

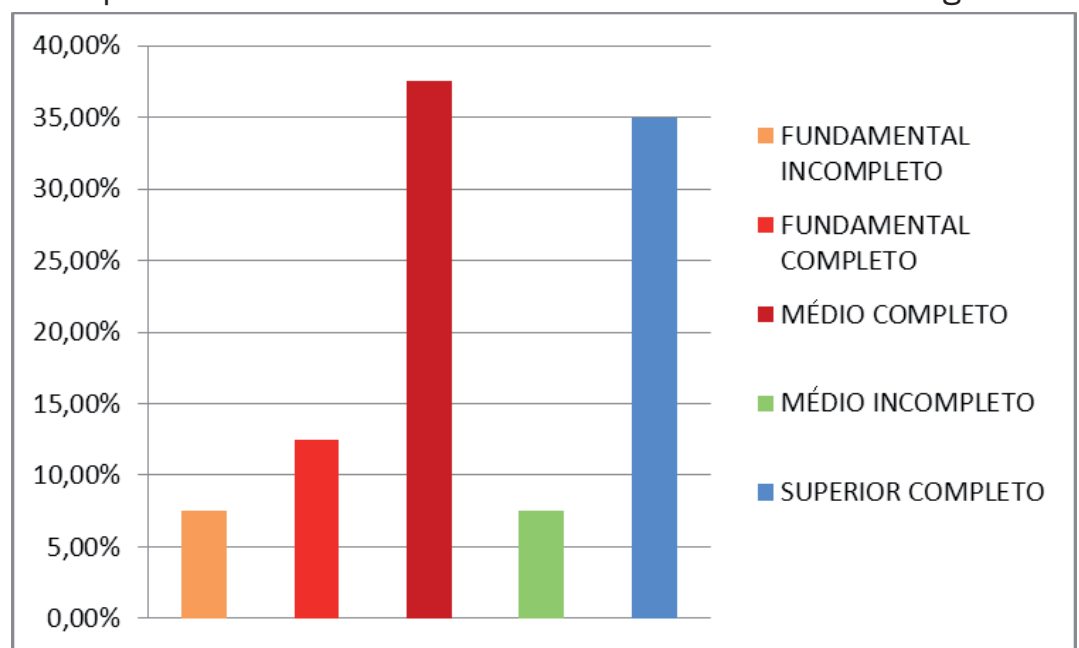

Figura 2. Grau de escolaridade dos consumidores das feiras livres nos municípios de Arcos e Formiga (MG). Fonte: Elaboração dos autores.

Em relação à renda familiar, 45 \% recebiam de um a três salários mínimos, 7,5 \% possuíam uma renda de sete a onze salários mínimos e 2,5 \% perfaziam acima de 12 salários mínimos (Figura 3). Por outro lado, as despesas familiares de $42,5 \%$ dos consumidores entrevistados ultrapassavam mil reais; $37,5 \%$ tinham uma despesa mensal entre seiscentos e mil reais e $20 \%$ disseram que suas despesas não ultrapassavam os seiscentos reais. 


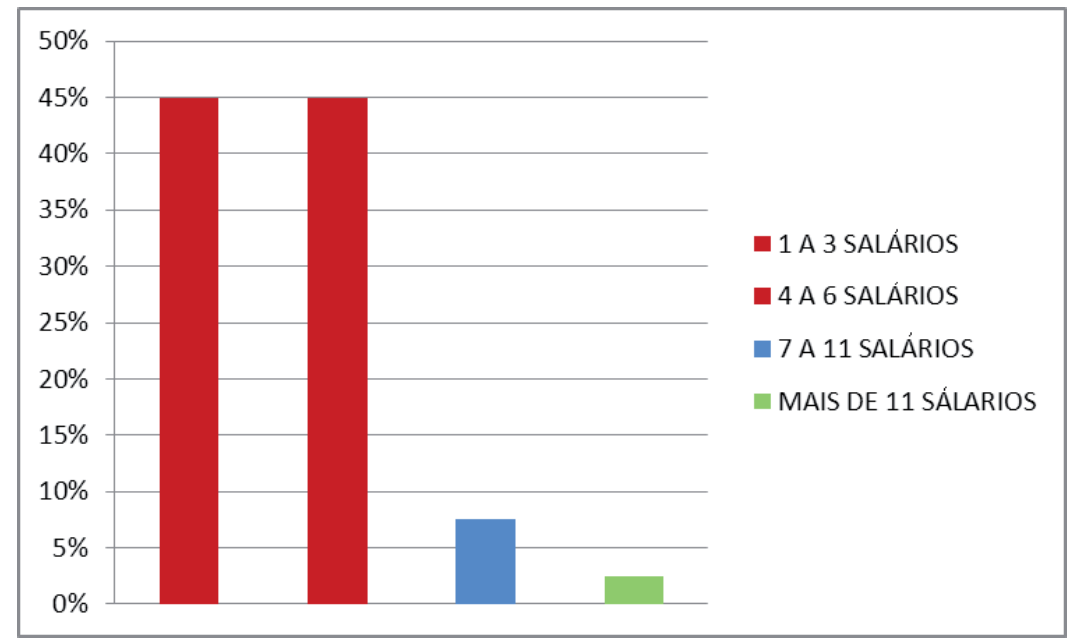

Figura 3. Renda mensal média dos consumidores das feiras livres nos municípios de Arcos e Formiga (MG). Fonte: Elaboração dos autores.

Quanto à ocupação profissional, 70 \% trabalhavam como autônomos em atividades comerciais, rurais, industriais ou serviços. Os outros $30 \%$ declararam-se inativos profissionalmente ou aposentados. Portanto, mesmo trabalhando todos os dias, para muitos, acordar cedo aos fins de semana já se tornou uma tradição.

Foi possível notar, por meio de observação não participante, a existência de um atendimento personalizado para os consumidores mais assíduos. Inclusive com o tratamento pelo nome e/ou apelido. Nesses casos, os vendedores guardam os itens que esses consumidores costumam levar.

Outra observação que chamou a atenção é que nas primeiras horas da feira, os consumidores mais frequentes geralmente são compradores de uma classe social mais alta. Na verdade, são pessoas que priorizam a qualidade dos produtos e apreciam a pouca movimentação do local. Mais para o final da feira, as pessoas que costumam fazer compras nesses horários têm maior interesse em adquirir produtos por um preço mais baixo, deixando a qualidade para o segundo plano.

Essa característica foi verificada por Ribeiro et al. (2005), quando descreveram que, entre $6 \mathrm{~h}$ e 9h30 min, estão à venda os produtos com preços mais elevados e há a predominância de consumidores com maior poder aquisitivo; após $9 \mathrm{~h} 30$ min, a situação se inverte, ou seja, os preços caem e o número de pessoas com menor poder aquisitivo cresce.

No entanto, não se pode dizer que essa é uma regra, principalmente porque no meio do horário de funcionamento da feira, ou seja, no horário de pico, há pessoas tanto das classes sociais mais altas quanto das mais baixas. Ressalta-se que essa observação é qualitativa, pois foi de acordo com a observação dos pesquisadores.

Há ainda os frequentadores de feiras que chegam ao final. Esses não podem ser considerados consumidores padrões, pois não compram, apenas recebem doações ou recolhem as sobras para seu sustento, mas não deixam de fazer parte do fenômeno. Existem ainda as pessoas, em especial jovens, que também frequentam as feiras para comer pastel ou apenas para passearem. Cabe ressaltar que desses dois perfis, nenhum indivíduo quis responder ao questionário. Isso explica parcialmente os resultados observados na Figura 1 e expõe a feria livre como um espaço de socialização total (ÂNGULO, 2011).

$\mathrm{Na}$ busca do entendimento dos fatores culturais e psicológicos os dados apontaram que a preocupação com a saúde e o bem estar familiar são os principais motivos que levam os consumidores a frequentar as feiras livres. Do total, $65 \%$ frequentam a feira livre pela durabilidade, qualidade e variedade dos produtos e pela produção artesanal levando-os a pensar que os produtos não possuem 
agrotóxicos. 0 fato de as feiras livres propiciarem, em um único espaço, vários produtos com preços mais acessíveis foram respondidos por $12,5 \%$ dos consumidores.

Segundo Kinjo e Ikeda (2005), as feiras são locais onde muitas pessoas buscam o convívio social. Assim, quando foi perguntado aos consumidores se a feira era um bom lugar para o convívio social, 17,5 \% responderam que sim e um deles acrescentou: “(...) um lugar agradável de se estar, onde se encontra com amigos e com a própria natureza uma vez que a feira é realizada ao livre".

Isso foi confirmado pela observação não participante, pois foi verificado que muitos conhecidos encontravam-se em barracas onde faziam compras em comum e gastavam um bom tempo trocando e conversando sobre os mais diversos assuntos. Mesmo entre os consumidores e vendedores foi possível verificar uma interação social que muitas vezes se confundia com uma amizade.

Os demais respondentes (5\%) responderam que gostam de ir à feira pelo bom atendimento e pela informalidade na compra e venda dos produtos. A Figura 4 detalha essas constatações.

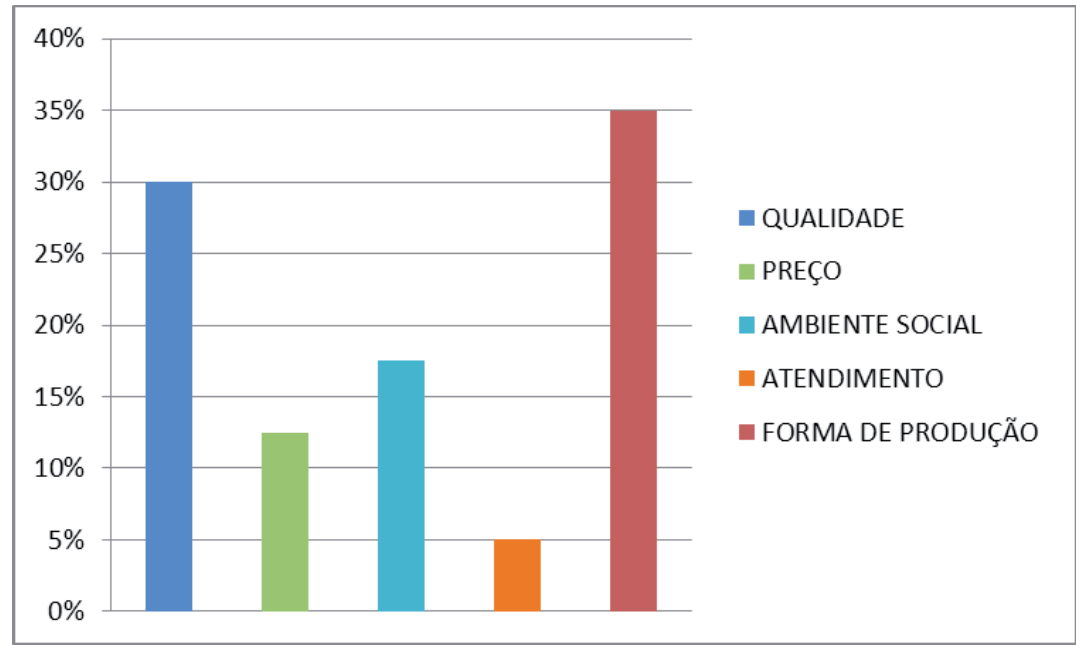

Figura 4. Principais motivos do consumo em feiras livres nos municípios de Arcos e Formiga (MG). Fonte: Elaboração dos autores.

Com relação a esse último fator, a pesquisa demonstrou que 37,5 \% dos consumidores das feiras livres dos municípios da microrregião de Formiga (MG) consideram o atendimento nas feiras livres muito bom, $35 \%$ consideram o atendimento excelente e 27,5 \% disseram que o atendimento é bom (Figura 5).

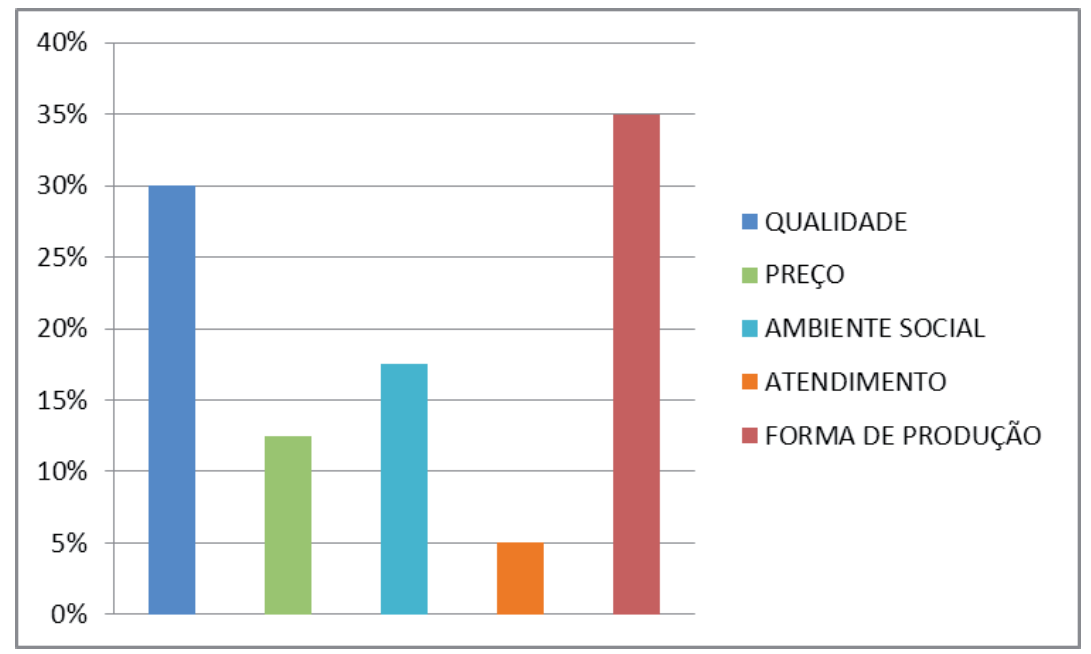

Figura 5. Principais motivos do consumo em feiras livres nos municípios de Arcos e Formiga (MG). Fonte: Elaboração dos autores. 
Os produtos mais procurados nas feiras pelos frequentadores foram: verduras e frutas (85 \%), queijos e derivados (7,5 \%), doces e quitandas (7,5 \%) (Figura 6). Os motivos já foram mencionados: qualidade, durabilidade, variedade e muitos gostam de comprar nas feiras livres porque encontram nesses espaços produtos que remetem a sua infância ou a vida no campo e porque gostam de saber que consumirão produtos sem agrotóxicos e com procedência conhecida.

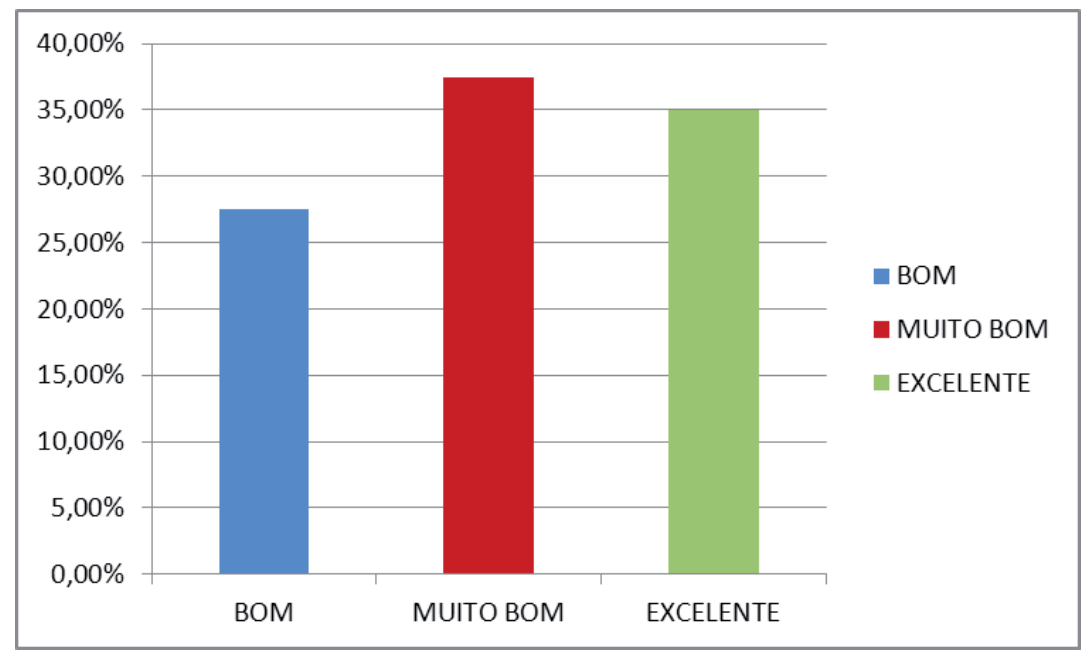

Figura 6. Principais produtos consumidos nas feiras livres nos municípios de Arcos e Formiga (MG).

Fonte: Elaboração dos autores.

Esse resultado é semelhante ao encontrado por Silva, Camara e Dalmas (2003), uma vez que a maioria busca produtos de primeira necessidade para suprir as famílias. Segundo o autor, os produtos mais adquiridos são, nesta ordem: hortifrutícolas, carnes vermelhas, pescado, cereais, especiarias e, por fim, vêm outros produtos, como roupas, utensílios domésticos, sapatos, produtos artesanais e produtos ilegais.

Com relação à qualidade dos produtos comercializados nas feiras livres, $85 \%$ dos entrevistados consideram superior aos produtos vendidos em outros estabelecimentos e apenas $10 \%$ consideram a qualidade semelhante. A Figura 7 detalha esses registros.

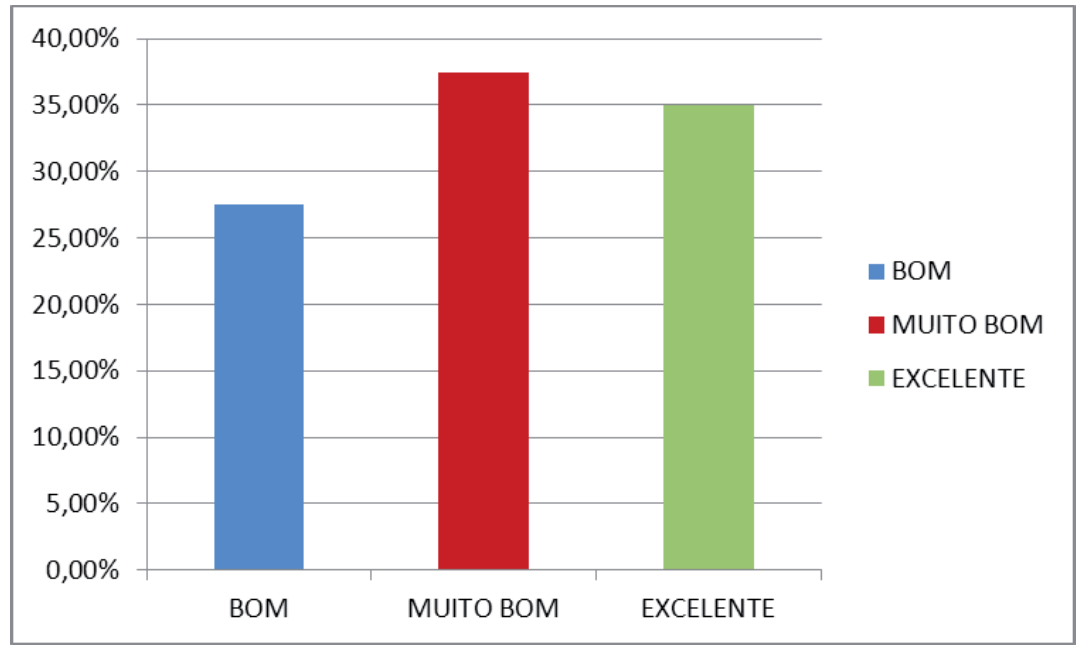

Figura 7. Qualidade do atendimento nas feiras livres nos municípios de Arcos e Formiga (MG).

Fonte: Elaboração dos autores. 
Ademais, observou-se que $82,5 \%$ das pessoas entrevistadas frequentam a feira livre toda semana contra $17,5 \%$ que disseram ir apenas duas ou menos vezes no mês, o que reforça a ideia de um espaço de socialização total (ÂNGULO, 2011).

\section{Conclusão}

O resultado das análises realizadas neste trabalho indicaram que as pessoas que compram nas feiras livres buscam, além dos produtos, o prazer de passear, encontrar amigos e lanchar. O comportamento variado dos consumidores é influenciado tanto por fatores socioeconômicos quanto por fatores culturais.

Com relação ao primeiro, percebeu-se que a maioria dos consumidores de feiras livres dessa região são pessoas adultas, casadas, com renda familiar baixa e média e ativas profissionalmente. No que se refere aos aspectos culturais, observou-se que a maioria dos consumidores buscam nas feiras livres melhoria da saúde e qualidade de vida. Esse fator sobrepôs à variável preço, apesar de ela ter sido um fator importante. Além disso, a feira é vista como um ambiente social agradável para todas as idades, pois muitos vão à feira para conversar com amigos e lanchar.

Esses resultados são de grande importância para os feirantes e autoridades públicas da região de estudo, uma vez que, a partir dos resultados, ficou claro que melhorar o atendimento, tornar o ambiente das feiras mais agradáveis e incentivar a produção de produtos orgânicos são fatores que podem impulsionar o consumo de produtos nas feiras livres das regiões estudadas, uma vez que os resultados mostraram que os consumidores procuram nesses ambientes saúde, qualidade de vida e lazer.

Como limitante da pesquisa tem-se o fato de ela ter sido realizada em uma região pequena e ser caracterizada como um estudo de caso único. Por isso, os dados aqui apresentados não podem ser generalizados para outras regiões.

\section{Analysis of the behavioral characteristics of free market consumers in the microregion of Formiga city}

\section{Abstract}

The paper analyzed the main social, economic and cultural factors that influenced the buying decision of consumers of free markets in the microregion of Formiga city, in Minas Gerais state. The results showed behavioral characteristics marked by variables that have valued the quality of life, time and money saving and social values, such as social interaction, influencing the behavior of consumption. Mostly, the consumers are poor and middle-income families.

Keywords: Behavioral variables. Family farming. Minas Gerais. Buying decision.

\section{Referências}

ANGULO, J. L. G. Mercado local, produção familiar e desenvolvimento: estudo de caso da feira de Turmalina, Vale do Jequitinhonha, MG. Organizações Rurais \& Agroindustriais, v. 5, n. 2, 2011. ASSEMBLÉIA LEGISLATIVA DE MINAS GERAIS (ALMG, 2015). Criação de Município e alteração de limites intermunicipais. Disponível em < https://www.almg.gov.br/consulte/ info_sobre_minas/index.html?aba $=$ js_tabMicrorregioes\&stlMicroregiao $=44>$ 
BARROS, M. A. B. ; LOPES, G. M. B. ; WANDERLEY, M. B. Tipologia do consumo de frutas: um estudo sobre o comportamento do consumidor de banana. Revista Produção Online, v. 7, n. 4, 2008.

BECKER, P. L. Métodos de pesquisa em ciências sociais. São Paulo: Hucitec, 1999.

CHURCHILL, G. A.; PETER, P. Marketing: criando valor para os clientes. Saraiva, 2000.

DEMO, P. Complexidade e aprendizagem: a dinâmica não linear do conhecimento. São Paulo: Atlas, 2002.

FOXALL, G. R. The behavior analysis of consumer choice: an introduction to the special issue. Journal of Economic Psycologhy, Amsterdam, v. 24, n. 5, p. 581-588, Mar. 2003.

GIL, A. C. Como elaborar projetos de pesquisa. São Paulo: Atlas, 2002.

GOGOY, W. I., SACCO DOS ANJOS, F. Estudo sobre a dimensão socioeconômica das feiras livres de Pelotas, RS (2007). Disponível em: < http://www.abhorticultura.com.br/biblioteca/ arquivos/Download/Biblioteca/olec4015.pdf>. Acesso em: 17 jul. 2015.

GOODE, W. J.; HATT, P. K. Métodos em pesquisa social: tradução de Carolina Martuscelli Bori. São Paulo, Ed. Nacional [1960], 1969.

JICK, T. D. Mixing qualitative and quantitative methods: triangulation in action. In: MAANEN, J. V. Qualitative methodology. London: Sage Publications, 1979.

KINJO, T.; IKEDA, A. Comportamento do consumidor em Feiras Livres. v. 7195, p. 120, 2005. Disponível em <http://sober.org.br/palestra/2/420.pdf>. Acesso em: 17 jul. 2015.

KOTLER, P. Administração de marketing: análise, planejamento, implementação e controle. 5. ed. São Paulo: Atlas, 1998. 725 p.

LAKATOS, E. M.; MARCONI, M. A. Técnicas de pesquisa: planejamento e execução de pesquisas, elaboração, análise e interpretação dos dados. 4. ed. São Paulo: Atlas, 1995. 206 p.

MARTINEZ, Steve. Local food systems: concepts, impacts, and issues. Diane Publishing, 2010.

RIBEIRO, E. M.; CASTRO, B. D.; SILVESTRE, L.; CALIXTO, J.; ARAÚJO, D.; GALIZONI, F.; AYRES, E. Programa de apoio às feiras e à agricultura familiar no Jequitinhonha mineiro. Agriculturas: experiências em agroecologia, Rio de Janeiro, v. 2, n. 2, p. 5-9, 2005.

RICOTTO, A. J. Uma rede de produção e comercialização alternativa para a agricultura familiar: 0 caso das feiras livres de Misiones, Argentina. 2002. Dissertação (Mestrado). Universidade Federal do Rio Grande do Sul, Porto Alegre, 2002.

ROESCH, S. M. A. Projetos de estágio e de pesquisa em administração: guias para estágios, trabaIhos de conclusão, dissertações e estudos de casos. São Paulo: Atlas, 1999.

SHETH, J. N.; GARDNER, D. M.; GARRETT, D. E. Marketing theory: evolution and evaluation. New York: Wiley, 1988. $231 \mathrm{p}$. 
SILVA, A. B.; GODOI, C. K.; BANDEIRA-DE-MELLO, R. (Org.). Pesquisa qualitativa em estudos organizacionais: paradigmas, estratégias e métodos. São Paulo: Saraiva, 2006.

SILVA, D. M.; CAMARA, M. R. G. da; DALMAS, L. C. Produtos orgânicos: barreiras para a disseminação do consumo de produtos orgânicos no varejo de supermercados em Londrina-PR. In: INTERNATIONAL CONFERENCE ON AGRI-FOOD CHAIN/NETWORKS ECONOMICS AND MANAGEMENT, 4., 2003, Ribeirão Preto. Anais... Ribeirão Preto, 2003.

SILVESTRE, L. H. A.; CALIXTO, J. S.; RIBEIRO, A. E. M. Mercados locais e políticas públicas para a agricultura familiar: um estudo de caso no município de Minas Novas, MG. In: CONGRESSO DA SOCIEDADE BRASILEIRA DE ECONOMIA E SOCIOLOGIA RURAL, 43., 2005, Ribeirão Preto. Anais... Ribeirão Preto: SOBER, 2005. 1 CD ROM.

SOLOMON, M. R. 0 comportamento do consumidor: comprando, possuindo e sendo. 5. ed. Porto Alegre: Bookman, 2002, 446 p.

THILMANY, D.; BOND, C. A.; BOND, J. K. Going local: Exploring consumer behavior and motivations for direct food purchases. American Journal of Agricultural Economics, v. 90, n. 5, p. 1303-1309, 2008.

THOMAS, J. R.; NELSON, J. K.; SILVERMAN, S. J. Métodos de pesquisa em educação física. Porto Alegre: Artmed, 2007.

TULL, D. S.; HAWKINS, D. I. Marketing research: meaning, measurement, and method - a text with cases. Macmillan, 1976.

VERGARA, S. C. Projetos e relatórios de pesquisa em administração. 3. ed. São Paulo: Atlas, 2000. 104 p. VILAS BOAS, L. H. B.; BRITO, M. J.; SETTE, R. S. Perspectivas da antropologia no estudo do comportamento do consumidor: contribuições para o desenvolvimento da teoria e pesquisa em marketing. Revista Eletrônica de Administração, v. 50, 2006.

VILAS BOAS, L. H.. Comportamento do consumidor de produtos orgânicos: uma análise na perspectiva da teoria da cadeia de meios e fins. 2005. 118 p. Tese (Doutorado em Administração) - Universidade Federal de Lavras, Minas Gerias, 2005.

YIN, R. K. Estudo de caso: planejamento e métodos. Porto Alegre: Brookman, 2001.

\section{Histórico editorial}

Submetido em: 17/07/2015

Aceito em: 12/11/2015 